\title{
Entry of Listeria monocytogenes in Mammalian Epithelial Cells: An Updated View
}

\author{
Javier Pizarro-Cerdá1,2,3, Andreas Kühbacher ${ }^{1,2,3}$, and Pascale Cossart ${ }^{1,2,3}$ \\ ${ }^{1}$ Institut Pasteur, Unité des Interactions Bactéries Cellules, Paris F-75015, France \\ ${ }^{2}$ INSERM, U604, Paris F-75015, France \\ ${ }^{3}$ INRA, USC2020, Paris F-75015, France \\ Correspondence: javier.pizarro-cerda@pasteur.fr; pascale.cossart@pasteur.fr
}

Listeria monocytogenes is a bacterial pathogen that promotes its internalization into host epithelial cells. Interaction between the bacterial surface molecules InIA and InIB and their cellular receptors E-cadherin and Met, respectively, triggers the recruitment of endocytic effectors, the subversion of the phosphoinositide metabolism, and the remodeling of the actin cytoskeleton that lead to bacterial engulfment. Additional bacterial surface and secreted virulence factors also contribute to entry, albeit to a lesser extent. Here we review the increasing number of signaling effectors that are reported as being subverted by L. monocytogenes during invasion of cultured cell lines. We also update the current knowledge of the early steps of in vivo cellular infection, which, as shown recently, challenges previous concepts generated from in vitro data.

Tisteria monocytogenes is a saprophytic gram$L_{\text {positive bacterium responsible for human }}$ listeriosis, a food-borne disease characterized in immunocompromised individuals by severe septicemia and meningoencephalitis; in pregnant women, placental infection can lead to meningoencephalitis of the newborn and abortion (Allerberger and Wagner 2010). The potential of L. monocytogenes to cause disease correlates with its capacity to survive within macrophages, to invade nonphagocytic cells and replicate therein (Fig. 1), and also to cross the intestinal, the blood-brain, and the fetoplacental barriers (Lecuit 2005; Cossart 2011). The proteins involved in cellular invasion and tissue tropism are encoded by the inlABgenelocus (Gaillard et al.
1991). The factors required for intracellular survival are encoded by the major virulence locus of L. monocytogenes. They include the secreted listeriolysin O (LLO) and two phospholipases involved in the disruption of phagosomal membranes and bacterial escape to the cytoplasm (Gaillard et al. 1987; Mengaud et al. 1987; Vázquez-Boland et al. 1992), the surface protein ActA that mediates the polymerization of cytoplasmic actin (Domann et al. 1992; Kocks et al. 1992) and favors cell-to-cell spread (Tilney and Portnoy 1989) as well as PrfA, the transcriptional activator of bacterial virulence genes (Leimeister-Wächter et al. 1990; Mengaud et al. 1991). Comparative genomic approaches on the pathogenic L. monocytogenes and the nonpathogenic

Editors: Pascale Cossart and Stanley Maloy

Additional Perspectives on Bacterial Pathogenesis available at www.perspectivesinmedicine.org

Copyright (C) 2012 Cold Spring Harbor Laboratory Press; all rights reserved; doi: 10.1101/cshperspect.a010009

Cite this article as Cold Spring Harb Perspect Med 2012;2:a010009 
J. Pizarro-Cerdá et al.

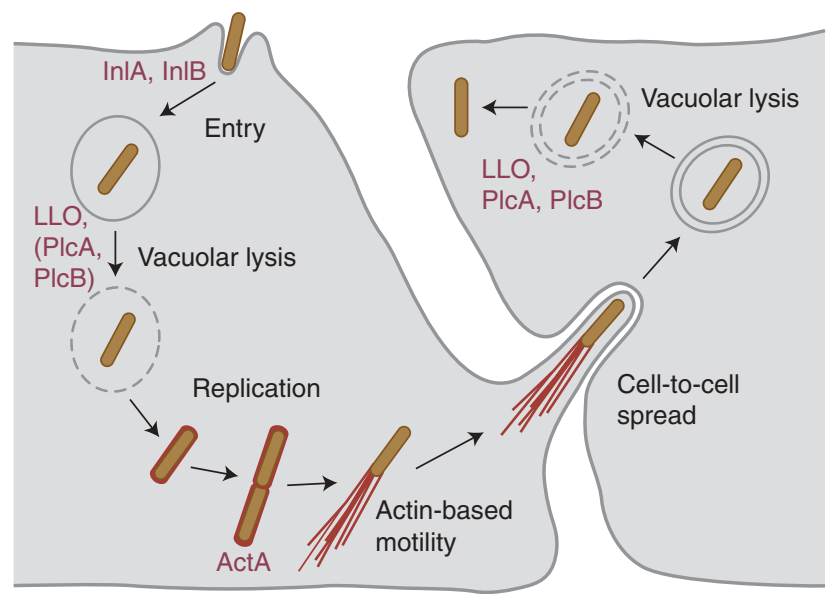

Figure 1. Intracellular cell cycle of L. monocytogenes. L. monocytogenes binds to epithelial host cells and promotes its own uptake in a process mediated by the two bacterial surface proteins InlA and InlB. The secreted poreforming toxin LLO (together with the bacterial phospholipases PlcA and PlcB, depending on the cell type) promotes vacuolar rupture and bacterial escape to the cytoplasm, where L. monocytogenes can replicate efficiently. Surface expression of ActA allows intracellular bacteria to polymerize host cell actin and to generate actin comet tails that propel L. monocytogenes through the cytoplasm and through membrane protrusions into neighboring cells. There, bacteria localize in a double membrane vacuole, which can be lysed by LLO, PlcA, and $\mathrm{PlcB}$ to start a new infection cycle.

Listeria innocua has led in recent years to the identification of many additional bacterial factors required for infection (Camejo et al. 2011; Cossart 2011). In this article, we will summarize our current understanding of bacterial effectors and cellular signaling cascades that are subverted by $L$. monocytogenes in order to invade mammalian epithelial cells.

\section{InIA AND InIB: TWO MAJOR VIRULENCE FACTORS INVOLVED IN CELL INVASION}

The two major invasion proteins of L. monocytogenes, InlA and InlB, belong to the so-called internalin family. Indeed, L. monocytogenes genome encodes 27 proteins now known as internalins, based on the presence of tandemly arranged leucine-rich repeats (LRRs) in their amino-terminal domain, which in several cases have been shown to be involved in protein-protein interactions with host-cell ligands (Marino et al. 2000; Cabanes et al. 2002; Bierne et al. 2007). Internalins are classified in three different groups according to their association to the L. monocytogenes surface through their carboxy- terminal domain: 21 internalins present LPXTG motifs that direct covalent protein anchoring to the cell wall peptidoglycan; this is the case for InlA, the prototype member of the family responsible for internalization-hence the name internalin - within a specific subset of host epithelial cells (Gaillard et al. 1991). InlB has been implicated in vitro in the invasion of a broad range of host cells. It is the only internalin characterized by repeats starting with the dipeptide GW (known as GW motifs) that promote loose interactions with the cell wall lipoteichoic acid (Dramsi et al. 1995; Braun et al. 1997; Jonquières et al. 1999). Four internalins lack anchoring motifs and are secreted: Among them, InlC interferes with NF- $\mathrm{KB}$ signaling and also perturbs cell-cell contacts intracellularly, promoting cell-to-cell spread (Rajabian et al. 2009; Gouin et al. 2010). So far, InlA and InlB are the only internalins that have been directly implicated in L. monocytogenes internalization within host cells; here we detail the signaling pathways activated by InlA and InlB (Fig. 2) as well as how other bacterial proteins potentiate invasion. 
A

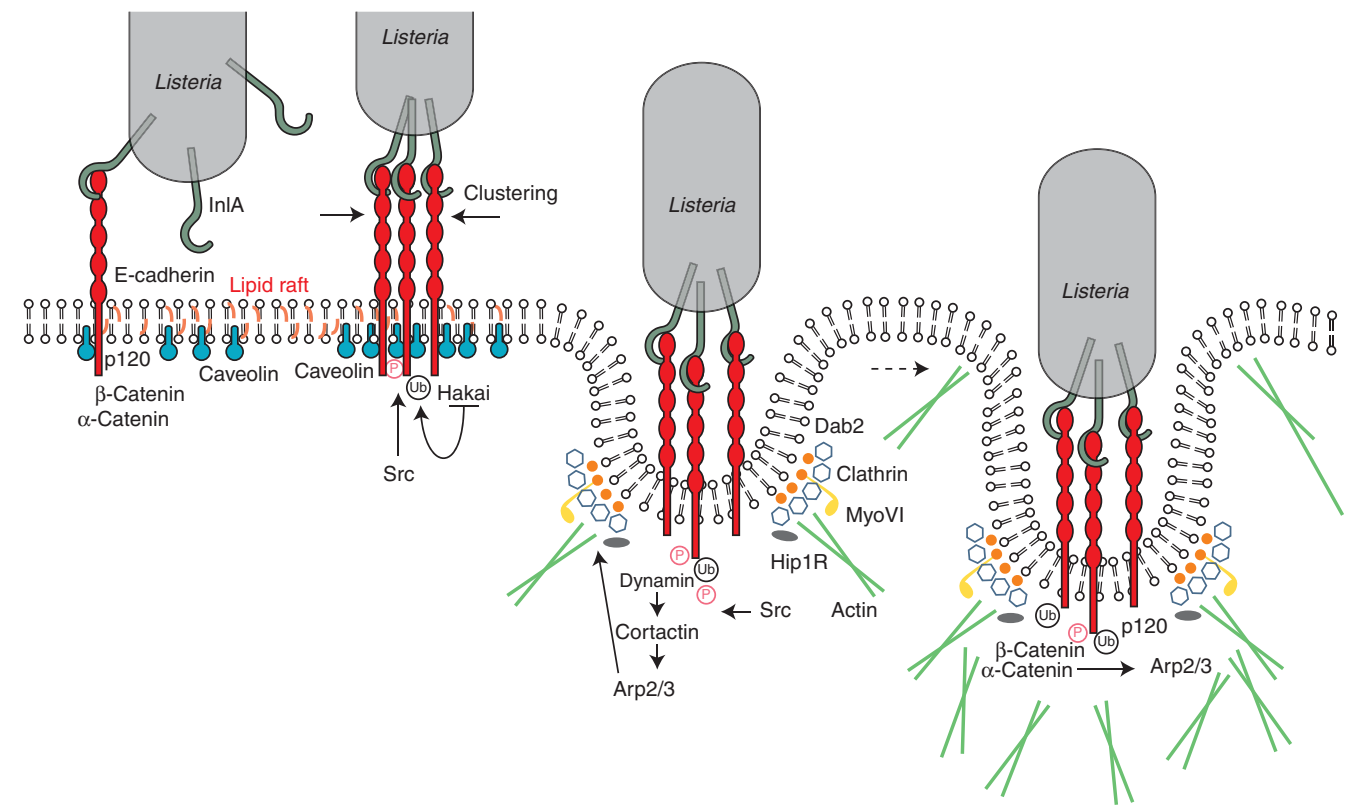

B

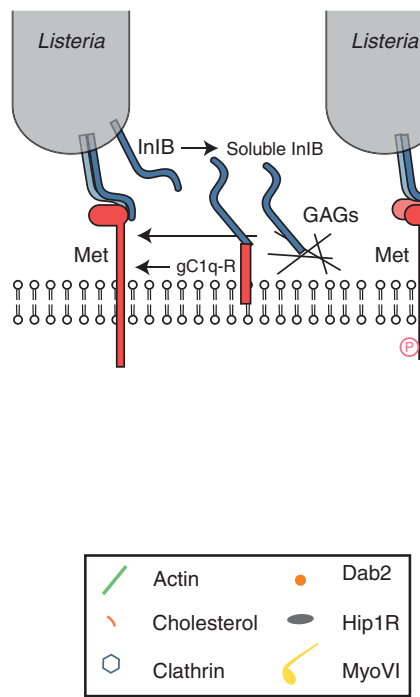

The InIB pathway

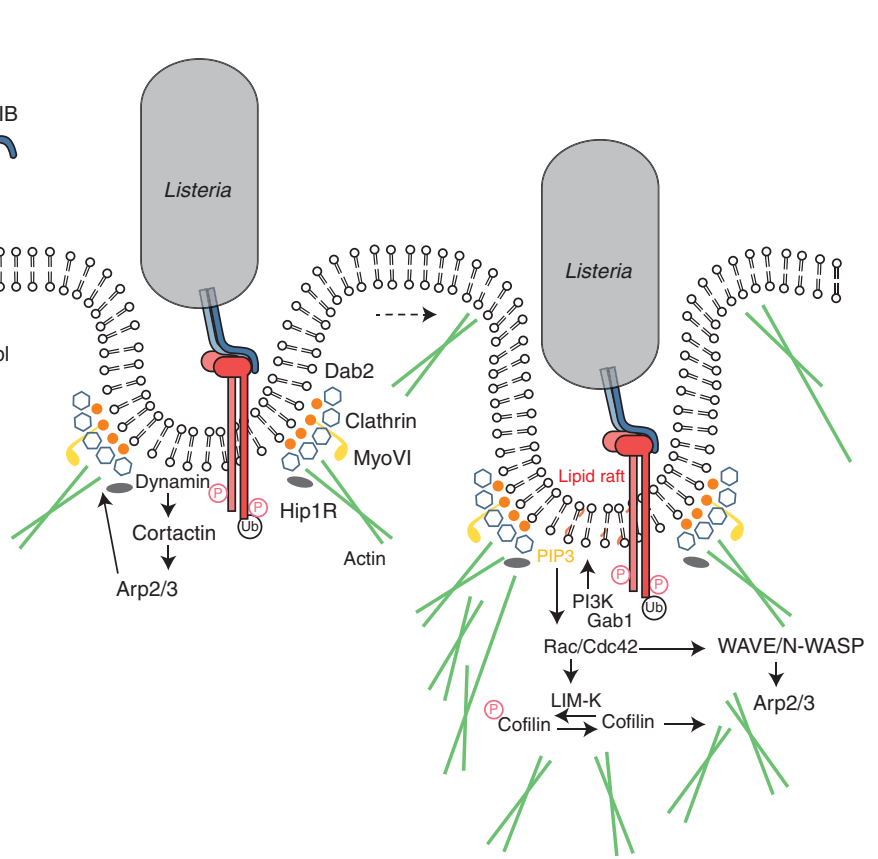

Figure 2. Signaling cascades activated via the InlA- and InlB-invasion pathways. Interaction of InlA and/or InlB with their respective host-cell surface receptors E-cadherin and Met induces ubiquitination of the receptors by the ubiquitin ligases Hakai in the case of E-cadherin or $\mathrm{Cbl}$ in the case of Met and subsequent recruitment of the clathrin endocytosis machinery (Dab2, clathrin, dynamin, Hip1R, MyoVI), which provides an initial platform for actin cytoskeleton polymerization. (See following page for legend.) 
J. Pizarro-Cerdá et al.

InIA Interacts with the Adhesion Molecule E-Cadherin to Promote Invasion in Specific Cellular Subpopulations

E-cadherin is an adhesion molecule involved in the formation of adherens junctions at the intestinal barrier, the blood-brain barrier, and the placenta, which has been identified as the cellular receptor for InlA (Mengaud et al. 1996). In mammalian tissues, polarized epithelial cells are characterized by the presence of several adhesion structures including tight and adherens junctions, which confer to a given organ impermeability to the external environment. Homophilic interactions between the extracellular domains of E-cadherin molecules in adjacent epithelial cells are required for the initial formation of adherens junctions; these structures are further stabilized by dynamic interactions of the Ecadherin cytoplasmic domain with elements of the clathrin-mediated endocytosis machinery and the actin cytoskeleton. As discussed below, L. monocytogenes subverts these cellular mechanisms to promote bacterial internalization. Interaction between the InlA LRRs and E-cadherin is sufficient to promote bacterial adhesion and entry into host cells: Indeed, LRRs expression on the surface of the noninvasive species L. innocua or on latex beads allows particle internalization in Caco-2 cells (Lecuit et al. 1997).

Remarkably, the InlA/E-cadherin interaction is species specific: A proline at position 16 of human or guinea pig E-cadherin is critical for its interaction with InlA, whereas a glutamic acid at the same position in mouse or rat E-cadherin precludes InlA recognition. Elegant studies have shown that expression of a murine E-cadherin displaying a proline instead of a glutamic acid at position 16 allows recognition of this molecule by InlA in vitro and in vivo (Lecuit et al. 1999, 2001). The crystal structure of the InlA LRRs in association with the first extracellular domain of the human E-cadherin has illustrated the molecular basis of this specificity: The proline 16 is accommodated in a hydrophobic pocket created by a deletion of one amino acid in the InlA LRR6, which shortens this repeat to 21 residues (instead of 22 observed in all other repeats); a bulky glutamic acid at this position does not fit the InlA LRRs hydrophobic pocket and prevents E-cadherin binding (Schubert et al. 2002). Owing to the specific distribution of E-cadherin in certain tissues, InlA plays a critical role in vivo in the bacterial traversal of the intestinal barrier and the tropism for the placenta (see below). Moreover, owing to its species-specific interaction with E-cadherin, InlA appears as the most important effector determining the susceptibility of a host to a L. monocytogenes infection.

\section{InIB Interacts with the Hepatocyte Growth Factor Receptor Met to Promote Internalization in a Wide Variety of Mammalian Cells}

InlB, which is encoded by the second gene of the inlAB locus (Gaillard et al. 1991), allows $L$. monocytogenes internalization in a broad range of cell lines including HeLa, HEp-2, HepG2, TIB73, and Vero cells (Dramsi et al. 1995; Lingnau et al. 1995; Braun et al. 1998, 1999; Greiffenberg et al. 1998). Several host-cell molecules have been identified as potential receptors for InlB; among them, the hepatocyte growth factor (HGF) receptor Met plays the most critical role for bacterial internalization (Shen et al. 2000). Met is a ubiquitous receptor tyrosine kinase that controls cell migration and growth during embryogenesis, as well as invasion and metastasis in cancer cells ( Trusolino and Comoglio 2002). The mature protein is a disulphide-linked heterodimer formed by a short extracellular $\alpha$ chain

Figure 2. (Continued) Downstream from E-cadherin, this first actin polymerization wave is activated by Src and cortactin, which promote recruitment of the Arp $2 / 3$ complex; association of $\beta / \alpha$-catenins to the bacterial entry sites favors dynamic interactions between the E-cadherin cytoplasmic tail and the actin cytoskeleton. In the case of Met, actin polymerization can be first coordinated by dynamin and cortactin upstream of the Arp $2 / 3$ complex, and subsequently by a signaling cascade downstream from the type IA PI 3-kinase, which involves the small GTPases Rac1 and Cdc42, abi1, WAVE, and N-WASP (depending on the cell type); LIM-K and cofilin play a critical role in the depolymerization of actin to allow completion of the bacterial internalization process. 
and a longer $\beta$ chain that comprises an ectodomain, a transmembrane domain, and a cytoplasmic tail where a kinase domain and phosphorylatable motifs are located (Birchmeier et al. 2003). InlB functionally mimics HGF, the natural Met ligand, through the binding of its LRRs (Braun et al. 1999; Marino et al. 1999; Niemann et al.2007). As in the case of the InlA/E-cadherin interaction, InlB interaction with Met is species specific: InlB interacts with human and mouse Met, but does not recognize the guinea-pig or rabbit receptor (Khelef et al. 2006). In susceptible species, InlB is reported to dimerize on binding to Met (Ferraris et al. 2010) leading to the receptor dimerization, the autophosphorylation of the protein-docking motifs, and the recruitment of protein effectors that induce signals to the actin cytoskeleton and the endocytosis machinery (see below). CD44v6, a member of the CD44 family of type I transmembrane glycoproteins, has been reported to potentiate Met activation by HGF and also by InlB (Orian-Rousseau et al. 2002; Ponta et al. 2003) but conflicting results exist concerning its implication during L. monocytogenes invasion (Jung et al. 2009; Dortet et al. 2010). The "B repeat" of InlB, often referred to as a spacer domain between the LRRs and GW modules, has also been reported to participate in the activation of Met and to endow InlB with stronger biological activities than those elicited by HGF (i.e., activation of a RasMAP kinase pathway) (Copp et al. 2003). However, structural studies indicate that it does not interact with Met, leading to the proposal that the $B$ repeat may interact with a nonidentified cellular receptor (Ebbes et al. 2011).

Although the amino-terminal LLR domain of InlB is critical for activating Met, the three carboxy-terminal GW modules are required to stabilize the InlB/Met interaction. As mentioned previously, the GW modules were originally described as mediating loose interactions between InlB and the lipoteichoic acids of the L. monocytogenes cell wall (Braun et al. 1997; Jonquières et al. 1999) and interestingly, soluble heparin can detach InlB from the bacterial cell wall (Jonquières et al. 2001). Heparin and glycosaminoglycans (GAGs), which are highly charged extracellular matrix polysaccharides, favor the surface clustering of growth factors including HGF, potentiating their activity by stabilizing their interaction with their receptors (Zhang 2010). Purified InlB was shown to bind to purified GAGs through its GW domains and invasion of Chinese hamster ovary $(\mathrm{CHO})$ cells is potentiated 10 -fold when GAGs are produced at the cell surface (Jonquières et al. 2001). These results suggest that the $\mathrm{GW}$ modules of InlB present the dual function of attaching InlB to the bacterial cell wall and of enhancing L. monocytogenes entry triggered by the LRRs domain, reinforcing the similarities between the mechanisms of cell activation exerted by InlB and HGF (Jonquières et al. 2001; Banerjee et al. 2004). The GW domains of InlB have been reported to bind another ubiquitous cellular molecule, the receptor of the globular part of the complement component $\mathrm{Clq}$ (gClq-R) (Braun et al. 2000; Marino et al. 2002). Intriguingly, gC1q-R is a glycosylphosphatidylinositol (GPI)-anchored protein that does not present a cytoplasmic domain, suggesting that signaling on interaction with InlB is transduced through another cofactor. It has been reported that interaction between gC1q-R and InlB GW domains antagonizes rather than enhances InlB signaling ( $\mathrm{Ma}$ rino et al. 2002; Banerjee et al. 2004). Therefore, the precise role of $\mathrm{gClq}-\mathrm{R}$ in $L$. monocytogenes infection remains to be clarified.

InlB expression by L. innocua does not induce bacterial adhesion to Vero cells (Jonquières et al. 1999) suggesting that InlB does not function as an adhesin but instead as a potent signaling invasin that mediates L. monocytogenes internalization through interactions with multiple host-cell ligands. The potential synergy of the InlA- and the InlB-invasion pathways has not been fully explored yet but it has been recently found that InlB plays, together with InlA, a critical role in the colonization of the placenta in vivo (Disson et al. 2008) (see below).

\section{The Clathrin-Mediated Endocytosis Machinery Is Involved in the Early Steps of Entry}

The clathrin-mediated endocytosis machinery is involved in the cell invasion by L. monocyto- 
J. Pizarro-Cerdá et al.

genes (Veiga and Cossart 2005; Veiga et al. 2007; Bonazzi et al. 2011). For both the InlA and the InlB pathways, the initial events in the internalization process are the posttranslational modifications of the two main Listeria receptors E-cadherin and Met: Indeed, E-cadherin is phosphorylated by Src and then ubiquitinated by Hakai (Bonazzi et al. 2008), whereas Met autophosphorylation leads to the recruitment of Cbl, which in turn ubiquitinates Met (Veiga and Cossart 2005). Recent studies have shown that the clathrin adaptor Dab2 is recruited to the L. monocytogenes receptors followed by the clathrin heavy and light chains; interestingly, the clathrin heavy chain is phosphorylated and this event is critical for the bacterial internalization process (Bonazzi et al. 2011). The protein Hip1R, which interacts with the clathrin light chain and also with the actin cytoskeleton, is then recruited; in addition, myosin VI can bind Hip1R and interact with actin filaments: Its capacity to move toward the minus end of the actin filaments fits well with a function in pulling the bacteria inside the cell (Bonazzi et al. 2011). Small interfering RNA (siRNA) experiments have shown that other members of the CME machinery play a critical role, in particular, dynamin (Veiga and Cossart 2005), which in turn can recruit cortactin, an activator of Arp2/ 3 , a main actin nucleator; a first wave of actin polymerization could thus be triggered by cortactin. Structural studies reveal that clathrincoated pits are present at the L. monocytogenes entry foci and are probably the sites of early actin rearrangements (Bonazzi et al. 2011). Interestingly, in JEG-3 epithelial cells, clathrin-independent mechanisms involving caveolin also mediate bacterial internalization downstream from the InlA-invasion pathway (Bonazzi et al. 2008).

Cytoskeletal and Membrane Rearrangements during Invasion Are Regulated by Actin-Binding Proteins, Small GTPases, PI 3-Kinase, and Phosphoinositides

As shown by numerous studies, following the first wave of actin polymerization described above or concomitantly, a second wave of actin rearrangements takes place during the L. monocytogenes invasion process, involving a PI 3-kinase, small GTPases of the Rho family, and several actin-binding proteins. The use of the PI 3-kinase inhibitors wortmannin and LY294002 showed in early studies that type IA PI 3-kinase activity is necessary for L. monocytogenes infection of Caco-2 and Vero cells via the InlAand InlB-invasion pathways, respectively (Ireton et al. 1996). In Caco-2 cells, however, no increase in $\mathrm{PI}(3,4) \mathrm{P}_{2}$ or $\mathrm{PI}(3,4,5) \mathrm{P}_{3}$ levels was detected on interaction with L. monocytogenes, because in these cells PI3 kinase is constitutively and highly expressed. On the contrary, 10- and 20 -fold increases on $\mathrm{PI}(3,4) \mathrm{P}_{2}$ or $\mathrm{PI}(3,4,5) \mathrm{P}_{3}$ levels are detected on infection of Vero cells with L. monocytogenes via the InlB-invasion pathway (Ireton et al. 1996). In these cells, activation of type IA PI 3-kinase is promoted by the protein adaptors Gab1, Cbl, and Shc, which are phosphorylated and recruited to the Met cytoplasmic tail, translocating with them the p85 subunit to the L. monocytogenes invasion foci (Ireton et al. 1999; Shen et al. 2000). Gab1 can also be translocated to the plasma membrane through its pleckstrin homology domain, which binds $\mathrm{PI}(3,4,5) \mathrm{P}_{3}$ (Basar et al. 2005) and indirectly boosts type IA PI 3-kinase activity via recruitment of the adaptor protein CrkII (Sun et al. 2005; Dokainish et al. 2007). $\mathrm{PI}(3,4,5) \mathrm{P}_{3}$ produced by the type IA PI 3-kinase plays a critical role in the recruitment of molecules that modulate actin cytoskeleton dynamics (see below) to the plasma membrane and a recent study has shown that the $5^{\prime}$-phosphatase OCRL restricts bacterial entry by precisely reducing the levels of $\mathrm{PI}(4,5) \mathrm{P}_{2}$ and $\mathrm{PI}(3,4,5) \mathrm{P}_{3}$ at $L$. monocytogenes entry foci (Kühbacher et al. 2012).

Actin polymerization following the InlB/ Met interaction differs among cell lines: In Vero cells, plasma membrane lipid rafts promote the clustering of $\mathrm{PI}(3,4,5) \mathrm{P}_{3}$ and favor the translocation of Racl to the plasma membrane (Seveau 2004; Seveau et al. 2007); together with the Wiskott-Aldrich syndrome protein (WASP)-related protein complex WAVE2, Rac1 promotes actin polymerization by the Arp $2 / 3$ complex (Bierne 2001; Bierne et al. 2005). In HeLa 
cells, Rac1 and Cdc42 are required for Arp2/3 activation downstream from $\mathrm{PI}(3,4,5) \mathrm{P}_{3}$, together with N-WASP, WAVE1, and WAVE2 (Bierne et al. 2005); in this cell line, $\mathrm{PI}(3,4,5) \mathrm{P}_{3}$ is also recognized by ARAP2, a protein that functions as a GAP for the small GTPase Arf6; ARAP2 promotes actin rearrangements during L. monocytogenes invasion in part by antagonizing the activity of Arf6 (Gavicherla et al. 2010). In murine fibroblasts, Cdc42 participates in the activation of Rac1 via PI 3-kinase-dependent and -independent mechanisms (Bosse et al. 2007). A recent systems-biology study has identified nine genes encoding known upstream regulators or downstream effectors of the type IA PI 3-kinase required for invasion of target cells by L. monocytogenes including the small GTPase Rab5 and several regulators of Arf or Rac1 small GTPases (Jiwani et al. 2011). PI4P, a phosphoinositide usually present at the Golgi and produced by type II PI 4-kinases, is detected at bacterial entry sites and is critical for invasion in LoVo and HeLa cells. PI4P does not seem to function as a $\mathrm{PI}(3,4,5) \mathrm{P}_{3}$ precursor but rather acts as an independent effector fostering bacterial invasion downstream from the tetraspanin CD81 (Pizarro-Cerdá et al. 2007; Tham et al. 2010).

Concerning the InlA/E-cadherin invasion pathway, inhibition of Src kinase with the pharmacological agent PP1 in L2071hEcad cells showed that phosphorylation of cortactin by Src contributes to the recruitment of the Arp2/ 3 complex to bacterial invasion foci and initiates actin polymerization (Sousa et al. 2007). Among the small GTPases of the Rho family known to control actin dynamics, only Rac1 (but not Cdc42 or RhoA) appeared to be required for L. monocytogenes entry in Caco-2 cells (Sousa et al. 2007). The interactions between E-cadherin and the actin cytoskeleton are highly complex (Yamada et al. 2005). In both adherens junction formation and internalization of Listeria, they involve $\alpha$ and $\beta$ catenins (Lecuit et al. 2000). A two-hybrid screen using $\alpha$-catenin as bait identified the autosomal recessive hypercholesterolemia GTPase-activating protein 10 (ARHGAP10) as a molecule required for $\alpha$-catenin recruitment and actin cytoskele- ton rearrangements during L. monocytogenes invasion (Sousa et al. 2005a). However, ARHGAP10 promotes GTP hydrolysis by Cdc42 and RhoA but not Racl; because Cdc42 and RhoA are not involved in InlA mediated entry, ARHGAP10 may function as an adaptor protein rather than GAP favoring interactions between $\alpha$-catenin and still nonidentified molecular partners during bacterial internalization. The unconventional Myosin VIIa has also been identified as a binding partner of the transmembrane molecule vezatin and E-cadherin in the InlA-invasion pathway and could participate, together with actin, in membrane rearrangements required for bacterial entry (Sousa et al. 2004).

Elongation of actin filaments and depolymerization of actin are tightly controlled events during L. monocytogenes internalization. Sequestration of the actin-binding proteins Ena/ VASP to the mitochondria (by the expression of mitochondrial targeting motifs) as well as siRNA inactivation of VASP inhibit the entry of bacteria or InlB-coated beads in Vero cells, demonstrating a role for VASP in entry (Bierne et al. 2005). In addition, overexpression of the LIM kinase, which phosphorylates and inactivates the actin depolymerizing factor cofilin, induces the accumulation of actin filaments beneath bacteria in Vero and REF-52 cells, preventing internalization and showing that actin depolymerization is critical during the late stages of the entry process (Bierne 2001). Interestingly, phosphorylated cofilin also drives phosphatidylcholine cleavage by host-cell phospholipase D1 (PLD1) and perturbation of the cellular levels of PLD1 blocks L. monocytogenes entry in Vero and HepG2 cells (Han et al. 2011).

Among the many other cellular actin interacting partners, septins represent a group of small GTPases known to polymerize into oligomeric protein complexes and filaments (Surka et al. 2002) that regulate cytokinesis, vesicle transport, and intracellular compartmentalization in a wide range of organisms (Beites et al. 2005; Estey et al. 2011). A member of the septin family, SEPT9, was initially identified as being recruited together with actin to the entry site of InlB-coated beads in LoVo cells (Pizarro- 
J. Pizarro-Cerdá et al.

Cerdá et al. 2002). Yeast two-hybrid screens and immunoprecipitation experiments revealed the interaction of SEPT9 with SEPT2, SEPT7, and SEPT11 in resting or InlB-stimulated HeLa cells (Mostowy et al. 2009a,b) and atomic force microscopy has shown that SEPT2 and SEPT9 contribute to the anchorage of Met to the actin cytoskeleton (Mostowy et al. 2011). Inactivation of septins by siRNA highlighted different contributions of SEPT2 and SEPT11 to L. monocytogenes invasion: SEPT2 knockdown severely modifies the actin cytoskeleton and inhibits bacterial entry (Mostowy et al. 2009b), whereas SEPT11 knockdown increases hostcell infection without modifying the actin cytoskeleton or affecting the Met signaling pathway, suggesting that SEPT11 rather restricts the InlB-mediated cell invasion (Mostowy and Cossart 2009).

In summary, the multiple interactions between the clathrin-mediated endocytosis machinery, the various phosphoinositides, and the actin cytoskeleton during $L$. monocytogenes cellular invasion highlight a very complex process whose dynamics vary with the nature of the infected cell. Genome-wide siRNA screens in progress should help in deciphering the orchestration of the molecular events that are key to cellular infection, and will address, in particular, whether internal membrane components are shuttled to the plasma membrane during entry.

\section{Role of InIA and InIB in the Traversal of the Host Barriers In Vivo}

Different lines of evidence show a critical contribution of InlA during L. monocytogenes infection in vivo. Indeed, epidemiological studies (Olier et al. 2003; Jacquet et al. 2004) show that strains in which InlA is truncated and secreted are frequently found in asymptomatic carriers or in food products, whereas full-length InlA is present far more frequently in clinical strains, suggesting that expression of an intact InlA molecule correlates with full bacterial virulence. When E-cadherin was identified as the receptor for InlA (Mengaud et al. 1996), a role for this internalin in the traversal of the intestinal barrier was proposed because E-cadherin is an ad- hesion molecule localized at the basolateral surface of several cell types of the small intestine villi, including enterocytes (absorptive cells) and goblet (mucus-secreting) cells. Studies in guinea pigs, which express an E-cadherin recognized by InlA, as well as in transgenic mice expressing the human E-cadherin under the control of the $i F A B P$ intestinal promotor, have confirmed that the presence of InlA is required for the traversal of the small intestine barrier in vivo through enterocyte invasion (Lecuit et al. 2001). Of note, in enterocytes E-cadherin is mainly present at adherens junctions where molecules are hidden below tight junctions and therefore are not normally exposed to the lumen of the intestine (Sousa et al. 2005b). Using rabbit ligated ileal loops and Madin-Darby canine kidney (MCDK) cells as a polarized epithelium model, it has been proposed that L. monocytogenes does not disrupt the enterocyte tight junctions to gain access to E-cadherin, but instead interacts with exposed E-cadherin at sites where apoptotic cells are expelled and detached from the epithelium by extrusion, suggesting that L. monocytogenes exploits the dynamic nature of epithelial renewal and junctional remodeling in small intestinal villi to breach this barrier (Fig. 3) (Pentecost et al. 2006). Of note, infection of wild-type mice intragastrically with a L. monocytogenes strain expressing a modified InlA that binds murine Ecadherin suggested that InlB also participates in bacterial internalization at small intestine villi; experiments in MDCK cells suggest that InlB does not act as an adhesin but rather accelerates bacterial internalization by promoting endocytosis of junctional components (Pentecost et al. 2010). It has thus been proposed that InlA provides specificity of adhesion to exposed E-cadherin at the tip of small intestine villi and InlB activates Met to accelerate junction endocytosis and bacterial invasion of enterocytes.

A recent study in $i F A B P$ transgenic mice has identified several discrete locations where E-cadherin is luminally accessible, including extruding enterocytes at the tip of villi as described above, but also villus epithelial folds and particularly junctions between mucus-secreting goblet cells, which are recognized as the preferred 
Listeria monocytogenes Entry in Mammalian Epithelial Cells

Table 1. Cell lines used for the study of the InIA- and InlB-invasion pathways

\begin{tabular}{llll}
\hline Cell line & \multicolumn{1}{c}{ Species } & \multicolumn{1}{c}{ Cell type } & \multicolumn{1}{c}{ Receptors } \\
\hline Caco-2 & Human & Colorectal adenocarcinoma & E-cadherin and Met \\
CHO & Hamster & Ovary & Met \\
GPC16 & Guinea pig & Epithelial X & E-cadherin and Met \\
HeLa & Human & Cervix carcinoma & Met \\
HEp-2 & Human & Larynx carcinoma & Met \\
HepG2 & Human & Hepatocarcinoma & Met \\
JEG-3 & Human & Trophoblasts & E-cadherin and Met \\
L2071hEcad & Mouse & Fibroblasts & E-cadherin and Met \\
LoVo & Human & Colorectal carcinoma & E-cadherin and Met \\
REF-52 & Rat & Embryonic fibroblasts & Met \\
TIB73 & Mouse & Embryonic hepatocyte & Met \\
Vero & African green monkey & Kidney & Met \\
\hline
\end{tabular}

Studies of the InlA and InlB pathways have been performed in different human and mammalian cell lines. Although some of them express both L. monocytogenes receptors, E-cadherin and Met, allowing the bacterium to enter by both pathways in concert or individually if either InlA or InlB is deleted, other cell lines do not express E-cadherin and can therefore only be used for studies concerning the InlB-invasion pathway.

sites for L. monocytogenes translocation at the small intestine (Nikitas et al. 2011). The InlAdependent bacterial translocation through goblet cells is extremely rapid and surprisingly LLO and ActA independent; pharmacological and microscopical analyses reveal that L. monocytogenes does not escape from its internalization vacuole in goblet cells and rather takes advantage of a transcytosis mechanism that allows fast traversal of the small intestinal barrier (Fig. 3) (Nikitas et al.2011). Although the small intestine is a major site for L. monocytogenes invasion, experiments in gerbils, which are natural hosts for L. monocytogenes, and in humanized transgenic mice that express E-cadherin in all physiological tissues, show that bacterial InlA-dependent translocation can also be observed at the caecum and the colon of the large intestine (Disson et al. 2008). Studies in rat ligated ileal loops from the lower part of the small intestine suggest furthermore that Peyer's patches, which are lymphoid nodules lined by antigen-sampling microfold (M) cells, may represent L. monocytogenes InlA- and InlB-independent invasion sites at the intestinal level (Pron et al. 1998; Corr et al. 2006).

As mentioned above, epidemiological data indicate that full-length InlA is predominant in clinically isolated L. monocytogenes strains, and this is particularly striking in pregnancy-related cases, in which $100 \%$ of isolated strains display an intact InlA molecule (Jacquet et al. 2004). In the placenta, E-cadherin is particularly enriched at the continuous multinucleated syncytiotrophoblast layer, which contributes to the barrier function of this organ, and studies in placental explants from human fetoplacental listeriosis cases as well as in primary cell cultures and placental cell lines indicate that interaction between InlA and the syncytiotrophoblast E-cadherin is critical for the traversal of the fetoplacental barrier (Lecuit et al. 2004). During the first trimester of pregnancy, the syncytiotrophoblast overlies a cytotrophoblast layer, which also participates in the placental barrier, and analyses of first trimester human placental cultures suggest that cytotrophoblasts can also be targeted by L. monocytogenes via InlA/E-cadherin interactions or cell-to-cell spread from infected phagocytes (Robbins et al. 2010; Zeldovich et al. 2011). The conjugated action of InlA and InlB to fetoplacental listeriosis was originally debated: Although it was shown in human mature placental explants that InlB participated together with InlA to syncytiotrophoblast invasion (Lecuit et al. 2004), in the guinea-pig model no role was shown for InlA despite its permissiveness to the InlA pathway (Bakardjiev et al. 2006), and in the mouse model no role was observed for InlB despite its permissiveness to 
J. Pizarro-Cerdá et al.

the InlB pathway (Le Monnier et al. 2007). The different organization of the placenta in these animal models could partially account for differences reported in each of these studies. However, these apparently contradictory observations were subsequently explained when it was found in gerbils and knock-in mice ubiquitously expressing humanized E-cadherin, that placental infection by L. monocytogenes takes place only when both InlA- and InlB-invasion pathways are functional as in humans (Disson et al. 2008). It is not the case in the guinea pig in which Met is not a receptor for InlB (Khelef et al. 2006), and it is also not the case in the mouse in which E-cadherin is not a receptor for InlA (Lecuit et al. 1999).

\section{Modulation of InIA- and InIB-Dependent Invasion Pathways by Other Internalins}

To date, among the 27 known L. monocytogenes internalins, InlA and InlB are the major virulence factors implicated in cell invasion. Several studies suggest that other members of the internalin family may modulate L. monocytogenes invasion (Chatterjee et al. 2006) by behaving as adhesins, by indirectly affecting the surface exposure of InlA and/or InlB, or by directly interacting with putative novel cellular receptors. For example, expression of the LPXTG-anchored InlJ by $L$. innocua leads to bacterial adhesion (but no invasion) to human JEG-3 and HT29 polarized epithelial cells (Sabet et al. 2008), but its potential cell ligand has not been identified yet. The gene cluster inlGHE is required for full invasion of Caco- 2 cells by the L. monocytogenes EGDe strain and it has been hypothesized that its expression may indirectly modulate the bacterial cell wall organization, therefore affecting InlA presentation at the L. monocytogenes surface (Bergmann et al. 2002).

A particular case has been reported for InlF: Under standard cell culture conditions, no role has been observed for this LPXTG internalin during invasion of Caco-2 and HepG2 cells in vitro or during Balb/c mice infection in vivo (Dramsi et al. 1997). However, in human HeLa and HEp-2 cells, pharmacological inhibition of the RhoA/Rho kinase signaling pathway using the drug Y27632 increases bacterial adhesion in an InlF-dependent manner (Kirchner and Higgins 2008). Moreover, in murine TIB75 hepatocytes and L2 fibroblasts, Y27632 treatment promotes InlF-dependent cell invasion by L. monocytogenes or by L. innocua-expressing InlF (but not InlA or InlB); Balb/c mice exposure to the HA-1077 drug, which also inhibits Rho kinases, increases the InlF-dependent virulence of L. monocytogenes in vivo (Kirchner and Higgins 2008). The mechanisms by which the RhoA/Rho kinase signaling pathway affects infection are unknown: Because this cascade enhances the assembly of actin-myosin structures, it was hypothesized that perturbation of actin-myosin interactions may lead to the cell surface exposure of a nonidentified InlF hostcell receptor (Carragher et al. 2006).

For several internalins including InlI, no role has been attributed to date (Sabet et al. 2005). Interestingly, although InlC2 and InlD in the strain EGD do not participate in the invasion of Caco- 2 or S180 cells in vitro and do not contribute to bacterial virulence in BALB/c mice in vivo (Dramsi et al. 1997), these internalins are the major targets of the rabbit humoral response to L. monocytogenes, together with InlA (Yu et al. 2007). For other members of the internalin family, different roles in bacterial intracellular stages have been identified, as is the case for InlC, which perturbs NF- $\mathrm{kB}$ signaling (Gouin et al. 2010) and cell-to-cell spread (Rajabian et al. 2009), or InlK, which allows escape of autophagy (Dortet et al. 2011). There are 14 remaining internalins that have not been characterized yet.

\section{ROLE OF NONINTERNALIN MOLECULES IN BACTERIAL ADHESION AND INVASION}

Several molecules not belonging to the internalin family have been reported to contribute to the L. monocytogenes adhesion and invasion of host cells using in vitro systems. This is the case of LLO, a major virulence factor belonging to the family of cholesterol-dependent cytotoxins first identified as a molecule allowing phagosomal maturation arrest and phagosomal lysis that leads to bacterial escape to the cytoplasmic space 


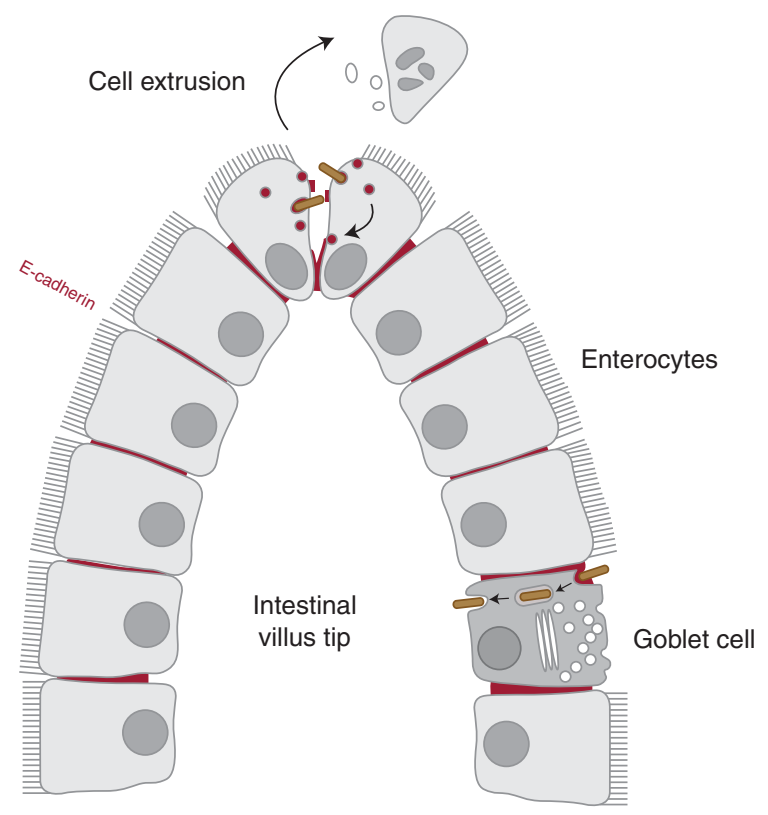

Figure 3. Traversal of the intestinal barrier by the InlA-E-cadherin interaction. The first contact between L. monocytogenes and host target cells takes place at the intestinal barrier level. E-cadherin, which is normally present at the basolateral face of enterocytes and therefore not exposed to the intestinal lumen, can be accessible to the L. monocytogenes invasion protein InlA at sites of apoptotic cell extrusion at the villus tip. However, the main route for bacterial translocation across the intestinal barrier is through mucus-secreting goblet cells via a rapid transcytosis mechanism that does not require intracellular bacterial escape from its internalizing vacuole.

(Gaillard et al. 1987; Dramsi and Cossart 2002; Henry et al. 2006). LLO secreted by extracellular bacteria has been shown to modulate a broad range of cellular activities including histone posttranscripional modifications (Hamon et al. 2007) as well as changes in the SUMOylation profile of host cells (Ribet et al. 2010) and several studies indicate that extracellular LLO also potentiates L. monocytogenes cell invasion in InlA/ InlB-dependent and -independent ways. Indeed, transient increases in cellular calcium from the extracellular milieu (and not from intracellular reservoirs) induced by extracellular LLO increase the InlB-dependent bacterial invasion of HEp-2 cells (Dramsi and Cossart 2003). Transient mitochondrial fragmentation, mitochondrial membrane potential loss, and drop in respiration and cellular ATP levels also correlate with the LLO-induced calcium fluxes and increased bacterial entry in HeLa cells, suggesting that the bioenergetic state of resting cells represents a barrier to L. monocytogenes invasion and the LLO-induced metabolic cell reprogramming promotes efficient bacterial internalization (Stavru et al. 2011); the molecular mechanisms that link this reprogramming with phagocytosis are currently unknown. A direct role for LLO in promoting bacterial adhesion to epithelial cells has been proposed (Krawczyk-Balska and Bielecki 2005), and a recent study shows that LLO is sufficient to induce L. monocytogenes entry in HepG2 and HeLa cells in the absence of InA or InlB signaling (Vadia et al. 2011). Indeed, L. innocua-expressing LLO or latex beads coated with LLO are internalized in a cholesterol-, dynamin-, tyrosine kinase-, and actin-dependent but clathrin-independent manner; interestingly, complete pore formation is critical because a LLO variant that binds to host cells but only assembles into a prepore complex fails to promote invasion. Although LLO seems therefore sufficient to trigger bacterial invasion, it is proposed that, by stimulating actin polymerization and endocytosis, this cholesterol-dependent 
J. Pizarro-Cerdá et al.

cytotoxin cooperates with InlA and InlB to potentiate efficient bacterial infection in a broad range of host cells (Vadia et al. 2011).

ActA is another major L. monocytogenes virulence factor that has been referred to play a role in bacterial invasion of host cells. ActA was first described as a protein promoting actin polymerization in the intracellular environment and bacterial cell-to-cell spread (Domann et al. 1992; Kocks et al. 1992). Heterologous expression of ActA in the nonpathogenic species L. innocua allows bacterial internalization in epithelial polarized and nonpolarized cells (Caco-2, MCDK, HeLa, and Vero) but not in COS-1 fibroblasts, suggesting that ActA is sufficient to directly activate an invasion pathway specific for epithelial cells (Suárez et al. 2001). The amino-terminal region of ActA is similar to the domain of the Plasmodium falciparum circumsporozoite protein involved in heparate sulfate recognition and hepatocyte binding (Pancake et al. 1992; Coppi et al. 2007) and it has been shown that the presence of heparan sulfate at the surface of $\mathrm{CHO}$ cells is required for the entry of $L$. monocytogenes in an ActA-dependent manner (Alvarez-Dominguez et al. 1997). The in vivo conditions in which the ActA invasion-associated function would be critical for virulence remain to be characterized.

Several cell membrane enzymes involved in the modification of the L. monocytogenes cell wall architecture have been also shown to affect bacterial adhesion and/or invasion in vitro as well as virulence in vivo. For example, the lipoteichoic acid modifiers GtcA (Promadej et al. 1999) and DltA (Abachin et al. 2002), the lipoprotein LpeA (Réglier-Poupet et al. 2003), the prolipoprotein diacylglyceryl transferase Lgt (Machata et al. 2008), and the protein MprF involved in the modification of the phospholipid lysylphosphatidylglycerol (Thedieck et al. 2006) play roles in L. monocytogenes adhesion or invasion in cell lines by probably modulating the electronegativity of the bacterial surface charge and/or altering the surface expression of adhesins/invasins. A particular class of cell membrane enzymes is the autolysins, which are involved in the digestion of the cell wall peptidoglycan: Among the six putative autolysins encoded by the L. monocyto- genes genome, three of them (Ami, Auto, and IspC) characterized by the presence of carboxyterminal GW repeats have been implicated in bacterial attachment to host cells or invasion. Ami, a $N$-acetylmuramoyl-L-alanine amidase (Braun et al. 1997) is required for adhesion but not for invasion of host cells in an $\triangle i n l A, \Delta i n l B$, or $\triangle i n l A B$ background only (Milohanic et al. 2000), and interestingly, the eight GW repeats of Ami are sufficient to promote L. monocytogenes adhesion to host cells (Milohanic et al. 2001). Auto, the only L. monocytogenes autolysin absent from the genome of L. innocua, is required for invasion (not adhesion) to several mammalian cell lines (Cabanes et al. 2004), whereas IspC is required for bacterial adhesion and/or invasion in a cell line-dependent manner (Wang and Lin 2008). Intriguingly, the $\Delta a m i, \Delta a u t o$, and $\triangle i s p C$ strains do not display major morphological abnormalities (ActA surface expression is only affected in the $\Delta i s p C$ mutant) suggesting that these molecules probably play a minor role as autolysins in vitro; their importance is highlighted by the reduced virulence of the mutant strains in the mouse model in vivo. The potential cellular ligands for these autolysins or the precise mechanisms governing their implication in adhesion and invasion have not been identified to date.

Other bacterial molecules involved in $L$. monocytogenes adhesion and/or invasion include the LPXTG protein Vip (Cabanes et al. 2005), the adhesins Lap (Jagadeesan et al. 2011), and LapB (Reis et al.2010) as well as the fibronectin-binding protein $\mathrm{A}(\mathrm{FbpA})$ required also as an escort protein for LLO and InlB (Dramsi et al. 2004).

\section{CONCLUDING REMARKS}

L. monocytogenes is a fascinating bacterial pathogen able to survive in a saprophytic environment and to induce disease in mammalian hosts. Adhesion to host cells and invasion of the intracellular space are critical steps for the traversal of host barriers leading to organ infection and bacterial spread in the organism; not surprisingly, many bacterial effectors have been shown to participate in every stage of the infectious process. We are starting to understand the 
global principles that govern the regulation of the expression of these virulence factors. The challenge for future studies is to understand how the combinatorial function of the bacterial and cellular factors specifically contributes to the pathophysiology of listeriosis in vivo.

\section{ACKNOWLEDGMENTS}

Research in P. Cossart's laboratory is supported by the Pasteur Institute, ERC advanced grant 233348, the Institut National de la Santé et de la Recherche Médicale, the Institut National de la Recherche Agronomique, the Agence Nationale de la Recherche, the Louis-Jeantet Foundation, and the Fondation Le Roch Les Mousquetaires. A.K. is a recipient of a scholarship from the Pasteur-Paris University International Doctoral Program/Institut Carnot Maladies Infectieuses.

\section{REFERENCES}

Abachin E, Poyart C, Pellegrini E, Milohanic E, Fiedler F, Berche P, Trieu-Cuot P. 2002. Formation of D-alanyl-lipoteichoic acid is required for adhesion and virulence of Listeria monocytogenes. Mol Microbiol 43: 1-14.

Allerberger F, Wagner M. 2010. Listeriosis: A resurgent foodborne infection. Clin Microbiol Infect 16: 16-23.

Alvarez-Dominguez C, Carrasco-Marín E, Leyva-Cobián F. 1993. Role of complement component C1q in phagocytosis of Listeria monocytogenes by murine macrophagelike cell lines. Infect Immun 61: 3664-3672.

Alvarez-Dominguez C, Vázquez-Boland JA, Carrasco-Marín E, López-Mato P, Leyva-Cobián F. 1997. Host cell heparan sulfate proteoglycans mediate attachment and entry of Listeria monocytogenes, and the listerial surface protein ActA is involved in heparan sulfate receptor recognition. Infect Immun 65: 78-88.

Bakardjiev AI, Theriot JA, Portnoy DA. 2006. Listeria monocytogenes traffics from maternal organs to the placenta and back. PLoS Pathog 2: e66.

Banerjee M, Copp J, Vuga D, Marino M, Chapman T, Van Der Geer P, Ghosh P. 2004. GW domains of the Listeria monocytogenes invasion protein InlB are required for potentiation of Met activation. Mol Microbiol 52: 257-271.

Basar T, Shen Y, Ireton K. 2005. Redundant roles for Met docking site tyrosines and the Gabl pleckstrin homology domain in InlB-mediated entry of Listeria monocytogenes. Infect Immun 73: 2061-2074.

Beites CL, Campbell KA, Trimble WS. 2005. The septin Sept5/CDCrel- 1 competes with $\alpha$-SNAP for binding to the SNARE complex. Biochem J 385: 347-353.

Bergmann B, Raffelsbauer D, Kuhn M, Goetz M, Hom S, Goebel W. 2002. InlA- but not InlB-mediated internali- zation of Listeria monocytogenes by non-phagocytic mammalian cells needs the support of other internalins. Mol Microbiol 43: 557-570.

Bierne H. 2001. A role for cofilin and LIM kinase in Listeriainduced phagocytosis. J Cell Biol 155: 101-112.

Bierne H, Miki H, Innocenti M, Scita G, Gertler FB, Takenawa T, Cossart P. 2005. WASP-related proteins, Abil and Ena/VASP are required for Listeria invasion induced by the Met receptor. J Cell Sci 118: 1537-1547.

Bierne H, Sabet C, Personnic N, Cossart P. 2007. Internalins: A complex family of leucine-rich repeat-containing proteins in Listeria monocytogenes. Microbes Infect 9: 11561166.

Birchmeier C, Birchmeier W, Gherardi E, Vande Woude GF. 2003. Met, metastasis, motility and more. Nat Rev Mol Cell Biol 4: 915-925.

Bonazzi M, Veiga E, Pizarro-Cerdá J, Cossart P. 2008. Successive post-translational modifications of E-cadherin are required for InlA-mediated internalization of Listeria monocytogenes. Cell Microbiol 10: 2208-2222.

Bonazzi M, Vasudevan L, Mallet A, Sachse M, Sartori A, Prevost MC, Roberts A, Taner SB, Wilbur JD, Brodsky FM, et al. 2011. Clathrin phosphorylation is required for actin recruitment at sites of bacterial adhesion and internalization. J Cell Biol 195: 525-536.

Bosse T, Ehinger J, Czuchra A, Benesch S, Steffen A, Wu X, Schloen K, Niemann HH, Scita G, Stradal TEB, et al. 2007. Cdc42 and phosphoinositide 3-kinase drive Racmediated actin polymerization downstream of c-Met in distinct and common pathways. Mol Cell Biol 27: 66156628.

Braun L, Dramsi S, Dehoux P, Bierne H, Lindahl G, Cossart P. 1997. InlB: An invasion protein of Listeria monocytogenes with a novel type of surface association. Mol Microbiol 25: 285-294.

Braun L, Ohayon H, Cossart P. 1998. The InIB protein of Listeria monocytogenes is sufficient to promote entry into mammalian cells. Mol Microbiol 27: 1077-1087.

Braun L, Nato F, Payrastre B, Mazié JC, Cossart P. 1999. The 213-amino-acid leucine-rich repeat region of the Listeria monocytogenes InlB protein is sufficient for entry into mammalian cells, stimulation of PI 3-kinase and membrane ruffling. Mol Microbiol 34: 10-23.

Braun L, Ghebrehiwet B, Cossart P. 2000. gC1q-R/p32, a $\mathrm{Clq}$-binding protein, is a receptor for the InlB invasion protein of Listeria monocytogenes. EMBO J 19: 14581466.

Cabanes D, Dehoux P, Dussurget O, Frangeul L, Cossart P. 2002. Surface proteins and the pathogenic potential of Listeria monocytogenes. Trends Microbiol 10: 238-245.

Cabanes D, Sousa S, Cebriá A, Lecuit M, García-Del Portillo F, Cossart P. 2005. Gp96 is a receptor for a novel Listeria monocytogenes virulence factor, Vip, a surface protein. EMBO J 24: 2827-2838.

Camejo A, Carvalho F, Reis O, Leitão E, Sousa S, Cabanes D. 2011. The arsenal of virulence factors deployed by Listeria monocytogenes to promote its cell infection cycle. Virulence 2: 379-394.

Carragher NO, Walker SM, Scott Carragher LA, Harris F, Sawyer TK, Brunton VG, Ozanne BW, Frame MC. 2006. Calpain 2 and Src dependence distinguishes 
J. Pizarro-Cerdá et al.

mesenchymal and amoeboid modes of tumer cell invasion: A link to integrin function. Oncogene 25: 57265740 .

Chatterjee SS, Otten S, Hain T, Lingnau A, Carl UD, Wehland J, Domann E, Chakraborty T. 2006. Invasiveness is a variable and heterogeneous phenotype in Listeria monocytogenes serotype strains. Int J Med Microbiol 296: 277-286.

Copp J, Marino M, Banerjee M, Ghosh P, Van Der Geer P. 2003. Multiple regions of internalin B contribute to its ability to turn on the Ras-mitogen-activated protein kinase pathway. J Biol Chem 278: 7783-7789.

Coppi A, Tewari R, Bishop JR, Bennett BL, Lawrence R, Esko JD, Billker O, Sinnis P. 2007. Heparan sulfate proteoglycans provide a signal to plasmodium sporozoites to stop migrating and productively invade host cells. Cell Host Microbe 2: 316-327.

Corr S, Hill C, Gahan CGM. 2006. An in vitro cell-culture model demonstrates internalin- and hemolysin-independent translocation of Listeria monocytogenes across $\mathrm{M}$ cells. Microb Pathogenesis 41: 241-250.

Cossart P. 2011. Illuminating the landscape of host-pathogen interactions with the bacterium Listeria monocytogenes. Proc Natl Acad Sci 108: 19848-19491.

Cossart P, Toledo-Arana A. 2008. Listeria monocytogenes, a unique model in infection biology: An overview. $\mathrm{Mi}$ crobes Infect 10: 1041-1050.

Disson O, Grayo S, Huillet E, Nikitas G, Langa-Vives F, Dussurget O, Ragon M, Le Monnier A, Babinet C, Cossart P, et al. 2008. Conjugated action of two speciesspecific invasion proteins for fetoplacental listeriosis. $\mathrm{Na}$ ture 455: 1114-1118.

Dokainish H, Gavicherla B, Shen Y, Ireton K. 2007. The carboxyl-terminal SH3 domain of the mammalian adaptor CrkII promotes internalization of Listeria monocytogenes through activation of host phosphoinositide 3-kinase. Cell Microbiol 9: 2497-2516.

Domann E, Wehland J, Rohde M, Pistor S, Hartl M, Goebel W, Leimeister-Wächter M, Wuenscher M, Chakraborty T. 1992. A novel bacterial virulence gene in Listeria monocytogenes required for host cell microfilament interaction with homology to the proline-rich region of vinculin. EMBO J 11: 1981-1990.

Dortet L, Veiga E, Bonazzi M, Cossart P. 2010. CD44-Independent activation of the Met signaling pathway by HGF and InlB. Microbes Infect 12: 919-927.

Dortet L, Mostowy S, Louaka AS, Gouin E, Nahori M-A, Wiemer EAC, Dussurget O, Cossart P. 2011. Recruitment of the major vault protein by InlK: A Listeria monocytogenes strategy to avoid autophagy. PLoS Pathog 7: e1002168.

Dramsi S, Cossart P. 2002. Listeriolysin O: A genuine cytolysin optimized for an intracellular parasite. J Cell Biol 156: $943-946$.

Dramsi S, Cossart P. 2003. Listeriolysin O-mediated calcium influx potentiates entry of Listeria monocytogenes into the human Hep-2 epithelial cell line. Infect Immun 71: 3614-3618.

Dramsi S, Biswas I, Maguin E, Braun L, Mastroeni P, Cossart P. 1995. Entry of Listeria monocytogenes into hepatocytes requires expression of inIB, a surface protein of the internalin multigene family. Mol Microbiol 16: 251-261.

Dramsi S, Dehoux P, Lebrun M, Goossens PL, Cossart P. 1997. Identification of four new members of the internalin multigene family of Listeria monocytogenes EGD. Infect Immun 65: 1615-1625.

Dramsi S, Bourdichon F, Cabanes D, Lecuit M, Fsihi H, Cossart P. 2004. FbpA, a novel multifunctional Listeria monocytogenes virulence factor. Mol Microbiol 53: 639_ 649.

Drevets DA, Bronze MS. 2008. Listeria monocytogenes: Epidemiology, human disease, and mechanisms of brain invasion. FEMS Immunol Med Mic 53: 151-165.

Ebbes M, Bleymüller WM, Cernescu M, Nölker R, Brutschy B, Niemann HH. 2011. Fold and function of the InlB B-repeat. J Biol Chem 286: 15496-15506.

Estey MP, Kim MS, Trimble WS. 2011. Septins. Curr Biol 21: R384-R387.

Ferraris DM, Gherardi E, Di Y, Heinz DW, Niemann HH. 2010. Ligand-mediated dimerization of the Met receptor tyrosine kinase by the bacterial invasion protein InlB. J Mol Biol 395: 522-532.

Gaillard JL, Berche P, Mounier J, Richard S, Sansonetti P. 1987. In vitro model of penetration and intracellular growth of Listeria monocytogenes in the human enterocyte-like cell line Caco-2. Infect Immun 55: 2822-2829.

Gaillard JL, Berche P, Frehel C, Gouin E, Cossart P. 1991. Entry of L. monocytogenes into cells is mediated by internalin, a repeat protein reminiscent of surface antigens from gram-positive cocci. Cell 65: 1127-1141.

Gaillard JL, Jaubert F, Berche P. 1996. The inlAB locus mediates the entry of Listeria monocytogenes into hepatocytes in vivo. J Exp Med 183: 359-369.

Gavicherla B, Ritchey L, Gianfelice A, Kolokoltsov AA, Davey RA, Ireton K. 2010. Critical role for the host GTPase-activating protein ARAP2 in InlB-mediated entry of Listeria monocytogenes. Infect Immun 78: 45324541.

Gouin E, Adib-Conquy M, Balestrino D, Nahori M-A, Villiers V, Colland F, Dramsi S, Dussurget O, Cossart P. 2010. The Listeria monocytogenes InlC protein interferes with innate immune responses by targeting the IкB kinase subunit IKK $\alpha$. Proc Natl Acad Sci 107: 1733317338.

Gregory SH, Sagnimeni AJ, Wing EJ. 1996. Expression of the inlAB operon by Listeria monocytogenes is not required for entry into hepatic cells in vivo. Infect Immun 64: 3983-3986.

Greiffenberg L, Goebel W, Kim KS, Weiglein I, Bubert A, Engelbrecht F, Stins M, Kuhn M. 1998. Interaction of Listeria monocytogenes with human brain microvascular endothelial cells: InlB-dependent invasion, long-term intracellular growth, and spread from macrophages to endothelial cells. Infect Immun 66: 5260-5267.

Hamon MA, Batsché E, Régnault B, Tham TN, Seveau S, Muchardt C, Cossart P. 2007. Histone modifications induced by a family of bacterial toxins. Proc Natl Acad Sci 104: $13467-13472$.

Han X, Yu R, Ji L, Zhen D, Tao S, Li S, Sun Y, Huang L, Feng Z, Li X, et al. 2011. InlB-Mediated Listeria monocytogenes internalization requires a balanced 
phospholipase D activity maintained through phosphocofilin. Mol Microbiol 81: 860-880.

Henry R, Shaughnessy L, Loessner MJ, Alberti-Segui C, Higgins DE, Swanson JA. 2006. Cytolysin-dependent delay of vacuole maturation in macrophages infected with Listeria monocytogenes. Cell Microbiol 8: 107-119.

Ireton K, Payrastre B, Chap H, Ogawa W, Sakaue H, Kasuga M, Cossart P. 1996. A role for phosphoinositide 3-kinase in bacterial invasion. Science 274: 780-782.

Ireton K, Payrastre B, Cossart P. 1999. The Listeria monocytogenes protein InlB is an agonist of mammalian phosphoinositide 3-kinase. J Biol Chem 274: 17025-17032.

Jacquet C, Doumith M, Gordon JI, Martin PMV, Cossart P, Lecuit M. 2004. A molecular marker for evaluating the pathogenic potential of foodborne Listeria monocytogenes. J Infect Dis 189: 2094-2100.

Jagadeesan B, Fleishman Littlejohn AE, Amalaradjou MAR, Singh AK, Mishra KK, La D, Kihara D, Bhunia AK. 2011. N-terminal Gly(224)-Gly(411) domain in Listeria adhesion protein interacts with host receptor Hsp60. PLoS ONE 6: e20694.

Jiwani S, Wang Y, Dowd GC, Gianfelice A, Pichestapong P, Gavicherla B, Vanbennekom N, Ireton K. 2011. Identification of components of the host type 1A phosphoinositide 3-kinase pathway that promote internalization of Listeria monocytogenes. Infect Immun 80: 1252-1266.

Jonquières R, Bierne H, Mengaud J, Cossart P. 1998. The inlA gene of Listeria monocytogenes LO28 harbors a nonsense mutation resulting in release of internalin. Infect Immun 66: 3420-3422.

Jonquières R, Bierne H, Fiedler F, Gounon P, Cossart P. 1999. Interaction between the protein InlB of Listeria monocytogenes and lipoteichoic acid: A novel mechanism of protein association at the surface of gram-positive bacteria. Mol Microbiol 34: 902-914.

Jonquières R, Pizarro-Cerda J, Cossart P. 2001. Synergy between the $\mathrm{N}$ - and C-terminal domains of InlB for efficient invasion of non-phagocytic cells by Listeria monocytogenes. Mol Microbiol 42: 955-965.

Jung C, Matzke A, Niemann HH, Schwerk C, Tenenbaum T, Orian-Rousseau V. 2009. Involvement of CD44v6 in InlB-dependent Listeria invasion. Mol Microbiol 72: 1196-1207.

Khelef N, Lecuit M, Bierne H, Cossart P. 2006. Species specificity of the Listeria monocytogenes InlB protein. Cell Microbiol 8: 457-470.

Kirchner M, Higgins DE. 2008. Inhibition of ROCK activity allows InlF-mediated invasion and increased virulence of Listeria monocytogenes. Mol Microbiol 68: 749-767.

Kocks C, Gouin E, Tabouret M, Berche P, Ohayon H, Cossart P. 1992. L. monocytogenes-induced actin assembly requires the actA gene product, a surface protein. Cell 68: 521-531.

Krawczyk-Balska A, Bielecki J. 2005. Listeria monocytogenes listeriolysin $\mathrm{O}$ and phosphatidylinositol-specific phospholipase C affect adherence to epithelial cells. Can J Microbiol 51: 745-751.

Kühbacher A, Dambournet D, Echard A, Cossart P, PizarroCerda J. 2012. Phosphatidylinositol 5-phosphatase oculocerebrorenal syndrome of Lowe protein (OCRL) con- trols actin dynamics during early steps of Listeria monocytogenes infection. J Biol Chem 287: 13128-13136.

Lecuit M. 2005. Understanding how Listeria monocytogenes targets and crosses host barriers. Clin Microbiol Infect 11: $430-436$.

Lecuit M, Ohayon H, Braun L, Mengaud J, Cossart P. 1997. Internalin of Listeria monocytogenes with an intact leucine-rich repeat region is sufficient to promote internalization. Infect Immun 65: 5309-5319.

Lecuit M, Dramsi S, Gottardi C, Fedor-Chaiken M, Gumbiner B, Cossart P. 1999. A single amino acid in E-cadherin responsible for host specificity towards the human pathogen Listeria monocytogenes. EMBO J 18: 39563963.

Lecuit M, Hurme R, Pizarro-Cerda J, Ohayon H, Geiger B, Cossart P. 2000. A role for $\alpha$-and $\beta$-catenins in bacterial uptake. Proc Natl Acad Sci 97: 10008-10013.

Lecuit M, Vandormael-Pournin S, Lefort J, Huerre M, Gounon P, Dupuy C, Babinet C, Cossart P. 2001. A transgenic model for listeriosis: Role of internalin in crossing the intestinal barrier. Science 292: 1722-1725.

Lecuit M, Nelson DM, Smith SD, Khun H, Huerre M, Vacher-Lavenu M-C, Gordon JI, Cossart P. 2004. Targeting and crossing of the human maternofetal barrier by Listeria monocytogenes: Role of internalin interaction with trophoblast E-cadherin. Proc Natl Acad Sci 101: 6152-6157.

Leimeister-Wächter M, Haffner C, Domann E, Goebel W, Chakraborty T. 1990. Identification of a gene that positively regulates expression of listeriolysin, the major virulence factor of Listeria monocytogenes. Proc Natl Acad Sci 87: $8336-8340$.

Le Monnier A, Autret N, Join-Lambert OF, Jaubert F, Charbit A, Berche P, Kayal S. 2007. ActA is required for crossing of the fetoplacental barrier by Listeria monocytogenes. Infect Immun 75: 950-957.

Lindén SK, Bierne H, Sabet C, Png CW, Florin TH, McGuckin MA, Cossart P. 2008. Listeria monocytogenes internalins bind to the human intestinal mucin MUC2. Arch Microbiol 190: 101-104.

Lingnau A, Domann E, Hudel M, Bock M, Nichterlein T, Wehland J, Chakraborty T. 1995. Expression of the Listeria monocytogenes EGD inlA and inlB genes, whose products mediate bacterial entry into tissue culture cell lines, by PrfA-dependent and -independent mechanisms. Infect Immun 63: 3896-3903.

Machata S, Tchatalbachev S, Mohamed W, Jänsch L, Hain T, Chakraborty T. 2008. Lipoproteins of Listeria monocytogenes are critical for virulence and TLR2-mediated immune activation. J Immunol 181: 2028-2035.

Madarame H, Seuberlich T, Abril C, Zurbriggen A, Vandevelde M, Oevermann A. 2011. The distribution of E-cadherin expression in listeric rhombencephalitis of ruminants indicates its involvement in Listeria monocytogenes neuroinvasion. Neuropath Appl Neuro 37: $753-$ 767.

Marino M, Braun L, Cossart P, Ghosh P. 1999. Structure of the lnlB leucine-rich repeats, a domain that triggers host cell invasion by the bacterial pathogen $L$. monocytogenes. Mol Cell 4: 1063-1072. 
J. Pizarro-Cerdá et al.

Marino M, Braun L, Cossart P, Ghosh P. 2000. A framework for interpreting the leucine-rich repeats of the Listeria internalins. Proc Natl Acad Sci 97: 8784-8788.

Marino M, Banerjee M, Jonquières R, Cossart P, Ghosh P. 2002. GW domains of the Listeria monocytogenes invasion protein InlB are SH3-like and mediate binding to host ligands. EMBO J 21: 5623-5634.

Mengaud J, Chenevert J, Geoffroy C, Gaillard JL, Cossart P. 1987. Identification of the structural gene encoding the SH-activated hemolysin of Listeria monocytogenes: Listeriolysin $\mathrm{O}$ is homologous to streptolysin $\mathrm{O}$ and pneumolysin. Infect Immun 55: 3225-3227.

Mengaud J, Dramsi S, Gouin E, Vazquez-Boland JA, Milon G, Cossart P. 1991. Pleiotropic control of Listeria monocytogenes virulence factors by a gene that is autoregulated. Mol Microbiol 5: 2273-2283.

Mengaud J, Ohayon H, Gounon P, Mege R-M, Cossart P. 1996. E-cadherin is the receptor for internalin, a surface protein required for entry of $L$. monocytogenes into epithelial cells. Cell 84: 923-932.

Milohanic E, Pron B, Berche P, Gaillard JL. 2000. Identification of new loci involved in adhesion of Listeria monocytogenes to eukaryotic cells. European Listeria Genome Consortium. Microbiology 146: 731-739.

Milohanic E, Jonquières R, Cossart P, Berche P, Gaillard JL. 2001. The autolysin Ami contributes to the adhesion of Listeria monocytogenes to eukaryotic cells via its cell wall anchor. Mol Microbiol 39: 1212-1224.

Mostowy S, Cossart P. 2009. From pathogenesis to cell biology and back. Cell Host Microbe 5: 510-513.

Mostowy S, Danckaert A, Tham TN, Machu C, Guadagnini S, Pizarro-Cerdá J, Cossart P. 2009a. Septin 11 restricts InlB-mediated invasion by Listeria. J Biol Chem 284: $11613-11621$.

Mostowy S, Tham TN, Danckaert A, Guadagnini S, Boisson-Dupuis S, Pizarro-Cerdá J, Cossart P. 2009b. Septins regulate bacterial entry into host cells. PLoS ONE 4: e4196.

Mostowy S, Janel S, Forestier C, Roduit C, Kasas S, PizarroCerdá J, Cossart P, Lafont F. 2011. A role for septins in the interaction between the Listeria monocytogenes invasion protein InlB and the Met receptor. Biophys J 100: 1949 1959.

Niemann HH, Jäger V, Butler PJG, van den Heuvel J, Schmidt S, Ferraris D, Gherardi E, Heinz DW. 2007. Structure of the human receptor tyrosine kinase met in complex with the Listeria invasion protein InlB. Cell 130: 235-246.

Nikitas G, Deschamps C, Disson O, Niault T, Cossart P, Lecuit M. 2011. Transcytosis of Listeria monocytogenes across the intestinal barrier upon specific targeting of goblet cell accessible E-cadherin. J Exp Med 208: 22632277.

Olier M, Pierre F, Rousseaux S, Lemaitre J-P, Rousset A, Piveteau P, Guzzo J. 2003. Expression of truncated Internalin A is involved in impaired internalization of some Listeria monocytogenes isolates carried asymptomatically by humans. Infect Immun 71: 1217-1224.

Orian-Rousseau V, Chen L, Sleeman JP, Herrlich P, Ponta H. 2002. CD44 is required for two consecutive steps in HGF/c-Met signaling. Genes Dev 16: 3074-3086.
Pancake SJ, Holt GD, Mellouk S, Hoffman SL. 1992. Malaria sporozoites and circumsporozoite proteins bind specifically to sulfated glycoconjugates. J Cell Biol 117: 13511357.

Pentecost M, Otto G, Theriot JA, Amieva MR. 2006. Listeria monocytogenes invades the epithelial junctions at sites of cell extrusion. PLoS Pathog 2: e3.

Pentecost M, Kumaran J, Ghosh P, Amieva MR. 2010. Listeria monocytogenes internalin $\mathrm{B}$ activates junctional endocytosis to accelerate intestinal invasion. PLoS Pathog 6: e1000900.

Peschard P, Fournier TM, Lamorte L, Naujokas MA, Band H, Langdon WY, Park M. 2001. Mutation of the c-Cbl TKB domain binding site on the Met receptor tyrosine kinase converts it into a transforming protein. $\mathrm{Mol}$ Cell 8: 995-1004.

Pizarro-Cerdá J, Jonquières R, Gouin E, Vandekerckhove J, Garin J, Cossart P. 2002. Distinct protein patterns associated with Listeria monocytogenes InlA- or InlB-phagosomes. Cell Microbiol 4: 101-115.

Pizarro-Cerdá J, Payrastre B, Wang Y-J, Veiga E, Yin HL, Cossart P. 2007. Type II phosphatidylinositol 4-kinases promote Listeria monocytogenes entry into target cells. Cell Microbiol 9: 2381-2390.

Pizarro-Cerdá J, Bonazzi M, Cossart P. 2010. Clathrin-mediated endocytosis: What works for small, also works for big. Bioessays 32: 496-504.

Ponta H, Sherman L, Herrlich PA. 2003. CD44: From adhesion molecules to signalling regulators. Nat Rev Mol Cell Biol 4: 33-45.

Promadej N, Fiedler F, Cossart P, Dramsi S, Kathariou S. 1999. Cell wall teichoic acid glycosylation in Listeria monocytogenes serotype $4 \mathrm{~b}$ requires gtcA, a novel, serogroup-specific gene. J Bacteriol 181: 418-425.

Pron B, Boumaila C, Jaubert F, Sarnacki S, Monnet JP, Berche P, Gaillard JL. 1998. Comprehensive study of the intestinal stage of listeriosis in a rat ligated ileal loop system. Infect Immun 66: 747-755.

Rajabian T, Gavicherla B, Heisig M, Müller-Altrock S, Goebel W, Gray-Owen SD, Ireton K. 2009. The bacterial virulence factor InlC perturbs apical cell junctions and promotes cell-to-cell spread of Listeria. Nat Cell Biol 11: 1212-1218.

Réglier-Poupet H, Pellegrini E, Charbit A, Berche P. 2003. Identification of LpeA, a PsaA-like membrane protein that promotes cell entry by Listeria monocytogenes. Infect Immun 71: 474-482.

Reis O, Sousa S, Camejo A, Villiers V, Gouin E, Cossart P, Cabanes D. 2010. LapB, a novel Listeria monocytogenes LPXTG surface adhesin, required for entry into eukaryotic cells. J Infect Dis 202: 551-562.

Ribet D, Hamon M, Gouin E, Nahori M-A, Impens F, Neyret-Kahn H, Gevaert K, Vandekerckhove J, Dejean A, Cossart P. 2010. Listeria monocytogenes impairs SUMOylation for efficient infection. Nature 464: 11921195.

Robbins JR, Skrzypczynska KM, Zeldovich VB, Kapidzic M, Bakardjiev AI. 2010. Placental syncytiotrophoblast constitutes a major barrier to vertical transmission of Listeria monocytogenes. PLoS Pathog 6: e1000732. 
Sabet C, Lecuit M, Cabanes D, Cossart P, Bierne H. 2005 LPXTG protein InlJ, a newly identified internalin involved in Listeria monocytogenes virulence. Infect Immun 73: 6912-6922.

Sabet C, Toledo-Arana A, Personnic N, Lecuit M, Dubrac S, Poupel O, Gouin E, Nahori M-A, Cossart P, Bierne H. 2008. The Listeria monocytogenes virulence factor InlJ is specifically expressed in vivo and behaves as an adhesin. Infect Immun 76: 1368-1378.

Schubert WD, Urbanke C, Ziehm T, Beier V, Machner MP, Domann E, Wehland J, Chakraborty T, Heinz DW. 2002. Structure of internalin, a major invasion protein of Listeria monocytogenes, in complex with its human receptor E-cadherin. Cell 111: 825-836.

Seveau S. 2004. Role of lipid rafts in E-cadherin- and HGFR/Met-mediated entry of Listeria monocytogenes into host cells. J Cell Biol 166: 743-753.

Seveau S, Tham TN, Payrastre B, Hoppe AD, Swanson JA, Cossart P. 2007. A FRET analysis to unravel the role of cholesterol in Racl and PI 3-kinase activation in the InlB/Met signalling pathway. Cell Microbiol 9: 790-803.

Shen Y, Naujokas M, Park M, Ireton K. 2000. InIB-dependent internalization of Listeria is mediated by the Met receptor tyrosine kinase. Cell 103: 501-510.

Sousa S, Cabanes D, El-Amraoui A, Petit C, Lecuit M, Cossart P. 2004. Unconventional myosin VIIa and vezatin, two proteins crucial for Listeria entry into epithelial cells. J Cell Sci 117: 2121-2130.

Sousa S, Cabanes D, Archambaud C, Colland F, Lemichez E, Popoff M, Boisson-Dupuis S, Gouin E, Lecuit M, Legrain P, et al. 2005a. ARHGAP10 is necessary for $\alpha$ catenin recruitment at adherens junctions and for Listeria invasion. Nat Cell Biol 7: 954-960.

Sousa S, Lecuit M, Cossart P. 2005b. Microbial strategies to target, cross or disrupt epithelia. Curr Opin Cell Biol 17: 489-498.

Sousa S, Cabanes D, Bougnères L, Lecuit M, Sansonetti P, Tran-Van-Nhieu G, Cossart P. 2007. Src, cortactin and Arp2/3 complex are required for E-cadherin-mediated internalization of Listeria into cells. Cell Microbiol 9 2629-2643.

Stavru F, Bouillaud F, Sartori A, Ricquier D, Cossart P. 2011. Listeria monocytogenes transiently alters mitochondrial dynamics during infection. Proc Natl Acad Sci 108: 3612-3617.

Suárez M, González-Zorn B, Vega Y, Chico-Calero I, Vázquez-Boland JA. 2001. A role for ActA in epithelial cell invasion by Listeria monocytogenes. Cell Microbiol 3: 853-864.

Sun H, Shen Y, Dokainish H, Holgado-Madruga M, Wong A, Ireton K. 2005. Host adaptor proteins Gabl and CrkII promote InlB-dependent entry of Listeria monocytogenes. Cell Microbiol 7: 443-457.

Surka MC, Tsang CW, Trimble WS. 2002. The mammalian septin MSF localizes with microtubules and is required for completion of cytokinesis. Mol Biol Cell 13: 3532 3545 .
Tham TN, Gouin E, Rubinstein E, Boucheix C, Cossart P, Pizarro-Cerdá J. 2010. Tetraspanin CD81 is required for Listeria monocytogenes invasion. Infect Immun 78: 204209.

Thedieck K, Hain T, Mohamed W, Tindall BJ, Nimtz M, Chakraborty T, Wehland J, Jänsch L. 2006. The MprF protein is required for lysinylation of phospholipids in listerial membranes and confers resistance to cationic antimicrobial peptides (CAMPs) on Listeria monocytogenes. Mol Microbiol 62: 1325-1339.

Tilney LG, Portnoy DA. 1989. Actin filaments and the growth, movement, and spread of the intracellular bacterial parasite, Listeria monocytogenes. J Cell Biol 109: 1597-1608.

Toledo-Arana A, Dussurget O, Nikitas G, Sesto N, GuetRevillet H, Balestrino D, Loh E, Gripenland J, Tiensuu T, Vaitkevicius K, et al. 2009. The Listeria transcriptional landscape from saprophytism to virulence. Nature 459: 950-956.

Trusolino L, Comoglio PM. 2002. Scatter-factor and semaphorin receptors: Cell signalling for invasive growth. Nat Rev Cancer 2: 289-300.

Vadia S, Arnett E, Haghighat A-C, Wilson-Kubalek EM, Tweten RK, Seveau S. 2011. The pore-forming toxin Listeriolysin $\mathrm{O}$ mediates a novel entry pathway of L. monocytogenes into human hepatocytes. PLoS Pathog 7: e1002356.

Vázquez-Boland JA, Kocks C, Dramsi S, Ohayon H, Geoffroy C, Mengaud J, Cossart P. 1992. Nucleotide sequence of the lecithinase operon of Listeria monocytogenes and possible role of lecithinase in cell-to-cell spread. Infect Immun 60: 219-230.

Veiga E, Cossart P. 2005. Listeria hijacks the clathrin-dependent endocytic machinery to invade mammalian cells. Nat Cell Biol 7: 894-900.

Veiga E, Guttman JA, Bonazzi M, Boucrot E, ToledoArana A, Lin AE, Enninga J, Pizarro-Cerdá J, Finlay BB, Kirchhausen T, et al. 2007. Invasive and adherent bacterial pathogens co-Opt host clathrin for infection. Cell Host Microbe 2: 340-351.

Wang L, Lin M. 2008. A novel cell wall-anchored peptidoglycan hydrolase (autolysin), IspC, essential for Listeria monocytogenes virulence: Genetic and proteomic analysis. Microbiology 154: 1900-1913.

Yu WL, Dan H, Lin M. 2007. Novel protein targets of the humoral immune response to Listeria monocytogenes infection in rabbits. J Med Microbiol 56: 888-895.

Zeldovich VB, Robbins JR, Kapidzic M, Lauer P, Bakardjiev AI. 2011. Invasive extravillous trophoblasts restrict intracellular growth and spread of Listeria monocytogenes. PLoS Pathog 7: e1002005.

Yamada S, Pokutta S, Drees F, Weiss WI, Nelson WJ. 2005. Deconstructing the cadherin-catenin-actin complex. Cell 123: 889-901.

Zhang L. 2010. Glycosaminoglycan (GAG) biosynthesis and GAG-binding proteins. Prog Mol Biol Transl Sci 93: 1-17. 


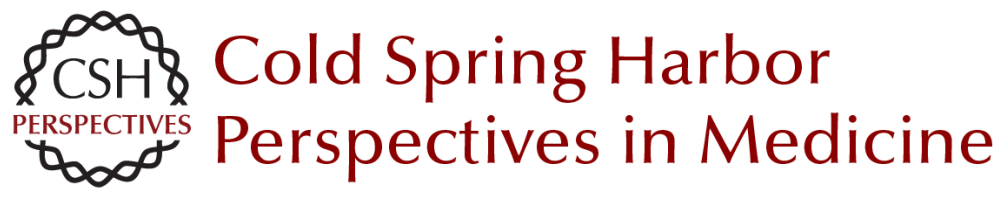

\title{
Entry of Listeria monocytogenes in Mammalian Epithelial Cells: An Updated View
}

\author{
Javier Pizarro-Cerdá, Andreas Kühbacher and Pascale Cossart
}

Cold Spring Harb Perspect Med 2012; doi: 10.1101/cshperspect.a010009

\section{Subject Collection Bacterial Pathogenesis}

Therapeutic and Prophylactic Applications of

Bacteriophage Components in Modern Medicine Sankar Adhya, Carl R. Merril and Biswajit Biswas

Vaccines, Reverse Vaccinology, and Bacterial

Pathogenesis

Isabel Delany, Rino Rappuoli and Kate L. Seib

Helicobacter and Salmonella Persistent Infection

Strategies

Denise M. Monack

Echoes of a Distant Past: The cag Pathogenicity Island of Helicobacter pylori

Nicola Pacchiani, Stefano Censini, Ludovico Buti, et al.

RNA-Mediated Regulation in Pathogenic Bacteria Isabelle Caldelari, Yanjie Chao, Pascale Romby, et al.

The Pneumococcus: Epidemiology, Microbiology, and Pathogenesis

Birgitta Henriques-Normark and Elaine I.

Tuomanen

Pathogenesis of Meningococcemia Mathieu Coureuil, Olivier Join-Lambert, Hervé Lécuyer, et al.

\section{Chlamydial Intracellular Survival Strategies}

Robert J. Bastidas, Cherilyn A. Elwell, Joanne N. Engel, et al.
Mechanisms and Biological Roles of

Contact-Dependent Growth Inhibition Systems

Christopher S. Hayes, Sanna Koskiniemi, Zachary C. Ruhe, et al.

A Genome-Wide Perspective of Human Diversity and Its Implications in Infectious Disease Jérémy Manry and Lluis Quintana-Murci

Host Specificity of Bacterial Pathogens Andreas Bäumler and Ferric C. Fang

The Inside Story of Shigella Invasion of Intestinal Epithelial Cells

Nathalie Carayol and Guy Tran Van Nhieu

Bartonella and Brucella--Weapons and Strategies for Stealth Attack

Houchaima Ben-Tekaya, Jean-Pierre Gorvel and Christoph Dehio

Concepts and Mechanisms: Crossing Host

Barriers

Kelly S. Doran, Anirban Banerjee, Olivier Disson, et al.

Genome Dynamics in Legionella: The Basis of

Versatility and Adaptation to Intracellular

Replication

Laura Gomez-Valero and Carmen Buchrieser

Mechanisms of Francisella tularensis Intracellular

Pathogenesis

Jean Celli and Thomas C. Zahrt

For additional articles in this collection, see http://perspectivesinmedicine.cshlp.org/cgi/collection/ 